\title{
DIROCOREMIA, SUBGEN.N. DE COREMIA AUDINET-SERVILLE (COLEOPTERA, CERAMBYCIDAE, COMPSOCERINI) ${ }^{1}$
}

\author{
Marinêz Isaac Marques ${ }^{2}$
}

\begin{abstract}
Dirocoremia, SUbGen.N. OF Coremla Audinet-SERVILle (Coleoptera, Cerambycidae, Compsocerini). Coremia (Dirocoremia), subgen.n., is proposed for Coremia ingae, sp.n., from Paraná, Brazil (type species) Coremia bruchi Gounelle, 1905 and Coremia simplicipes Gounelle, 1911.

KEY WORDS. Cerambycidae, Compsocerini, Coremia (Dirocoremia), new subgenus
\end{abstract}

Coremia A.-Serville, 1834, era constituído até o momento por três subgêneros e sete espécies (ZAJCIW 1959). A revisão do gênero (MARQUES 1994) possibilitou o reconhecimento de novos caracteres para definição dos subgêneros, levando ao estabelecimento de um novo subgênero e à descrição de uma nova espécie. Coremia bruchi Gounelle, 1905 e Coremia simplicipes Gounelle, 1911 são transferidos, respectivamente, de $C$. (Thalusia) e de $C$. (Lathusia) para o novo subgênero.

O material examinado pertence às seguintes Instituições: Coleção de Entomologia Pe. Jesus Santiago Moure, Departamento de Zoologia, Universidade Federal do Paraná, Curitiba (DZUP); Museu Anchieta, Porto Alegre (MAPA); Museu Nacional, Universidade Federal do Rio de Janeiro, Rio de Janeiro (MNRJ); Museu de Zoologia, Universidade de São Paulo, São Paulo (MZSP).

A terminologia adotada para a venação alar segue MARINONI \& ALMEIDA (1983); para terminália masculina EHARA (1954) e IUGA \& RosCA (1962) e a masculina e a feminina a de LINDROTH \& PALMEN (1970).

\section{Coremia (Dirocoremia), subgen.n.}

Coremia (Thalusia); Aurivillius, 1912: 335.- Zajciw, 1959: 276 (pantim).

Coremia (Lathusia) Zajciw, 1959: 278 (partim)

Espécie-tipo: Coremia (Dirocoremia) ingae, sp.n.

Diagnose. Cabeça pouco projetada à frente dos olhos; fronte evidentemente deprimida, com os bordos laterais elevados, formando um rebordo nítido entre a fronte e a área malar. Mandíbulas bordo cortante ao nível do meio, com dente aguçado, projetado e, na metade basal, irregular, com projeção dentiforme logo abaixo do dente mediano. Lobo ocular inferior pouco desenvolvido; ligação entre

1) Contribuição número 802 do Departamento de Zoologia, Universidade Federal do Paraná.

2) Departamento de Biologia/Zoologia, Instituto de Biociências. Universidade Federal de Mato Grosso, Av. Fernando Correa da Costa, 78090-390 Cuiabá, Mato Grosso, Brasil. Bolsista da CAPES. 
os lobos oculares mais estreita que o lobo superior e bem afastada do alvéolo antenal. Submento reduzido. Suturas gulares convergentes.

Antenas com evidente dimorfismo; nos machos, filiformes, ultrapassam o ápice elitral em 4-6 artículos; com fina pontuação pubescente, pouco aparente, adensada para os artículos distais; artículos cilíndrico-alongados, não expandidos para o ápice e não intumescidos; escapo robusto, piriforme, alargado na base; esta com uma ou duas depressões; com comprimento subigual à metade do III. Fêmeas: antenas não atingem ou ultrapassam pouco o ápice elitral; escapo com única depressão basal; artículos distais a partir do VIII, nítida e progressivamente mais curtos e intumescidos.

Protórax (Fig. 15) subanguloso ao nível do meio. Proendosternito (Fig. 19) com aspecto subtriangular. Processo mesosternal (Fig. 18) com entalhe mediano para encaixe do metasterno.

Élitros subparalelos; não deprimidos entre o úmero e o escutelo, o bordo anterior pouco projetado.

Fêmures com pubescência serícea esparsa; sem pêlos ou cerdas alongadas; os pedúnculos sulcados e carenados; os posteriores alongados, ultrapassam o ápice elitral por cerca da metade do comprimento das clavas; estas abruptas bem desenvolvidas. Tíbias posteriores deprimidas, arqueadas na metade distal, com ou sem tufo de pêlos.

Terminália. Fêmea: ovipositor (Figs 31,32) transverso, encurtado, tão longo quanto largo; região distal bífida com lobos laterais pouco diferenciados, com cerdas pouco aparentes e os estilos reduzidos.

\section{Coremia (Dirocoremia) ingae, sp.n.}

Figs 1, 4-34

Coremia (Thalusia) erythromera; Zajciw, 1959: 277 (partim)

Macho (Fig. 1). Colorido geral negro, antenas e pernas (exceto as clavas dos fềmures) vermelho-alaranjadas; tegumento opaco, superfície microcorrugada; pubescência da face dorsal negro-acastanhada, pouco aparente; face ventral revestida de pubescência serícea, menos evidente no metasterno.

Cabeça (Figs 4-6), na região posterior; não acentuadamente constrita, com comprimento subigual ao do protórax; superfície densamente pontuada, algo corrugada, com microescultura superficial. Fronte quase duas vezes mais larga que longa. Área malar pouco alongada, na menor largura subigual à metade do diâmetro do lobo ocular inferior; bordo anterior arredondado, pouco projetado. Lobo ocular inferior com a margem superior afastada do alvéolo antenal. Tubérculos anteníferos algo salientes, levemente acuminados. Sutura fronto-clipeal reta. Clípeo transverso, na linha média com comprimento subigual ao da fronte. Mandíbulas (Figs 8-9) truncadas no ápice; franja de pêlos reduzida. Lábio (Fig. 10): lígula no bordo apical com pilosidade pouco abundante e pouco alongada.

Antenas (Figs 1,11) ultrapassam o ápice elitral em 4-5 artículos. Escapo (Fig. 13) robusto, engrossado e largo para o ápice, com comprimento subigual à 

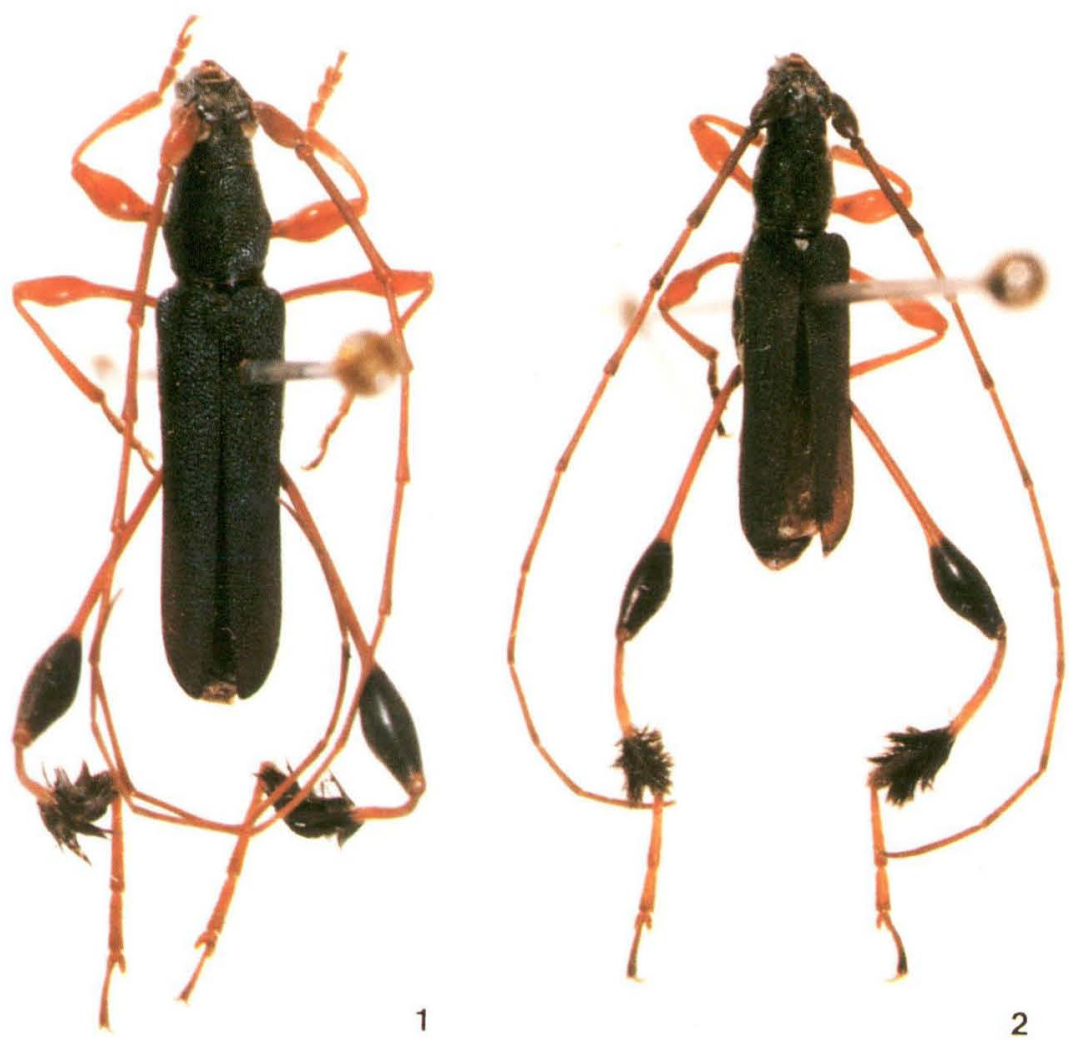

Figs 1-2. (1) Coremia (Dirocoremia) ingae, sp.n., holótipo macho, comprimeto $10 \mathrm{~mm}$; (2) Coremia (Dirocoremia) bruchi Gounelle, 1905, comprimento 8,3 mm.

metade do artículo III; na base com duas depressões longitudinais separadas por carena obtusa; pubescência negra, curta, a superfície microesculturada. Artículo III uma vez e meia tão longo quanto o IV; artículos VI-X com comprimentos subiguais e decrescentes, o XI tão longo quanto o III, levemente apendiculado. Fêmea: (Fig. 12) antenas não atingem o ápice elitral; escapo com única depressão basal, larga e bem impressa, algo estreitada para o bordo posterior; artículo XI com comprimento menor que a metade do comprimento do III, não apendiculado.

Prótorax (Fig. 15) com largura subigual ao comprimento; os bordos laterais regular e gradualmente atenuados para os bordos anterior e posterior, ao nível do meio algo expandidos e subangulosos; disco plano; superfície densamente pontuada-corrugada, os pontos com microescultura; pilosidade negro-acastanhada, pouco conspícua. Processo prosternal (Fig. 16) desenvolvido, com os bordos laterais ligeiramente expandidos para o ápice. Metasterno, no disco, com aspecto menos corrugado, a pubescência menos adensada do que no prosterno e mesosterno. Escutelo (Fig. 17) transverso, com o bordo apical arredondado; pubescência castanha. 


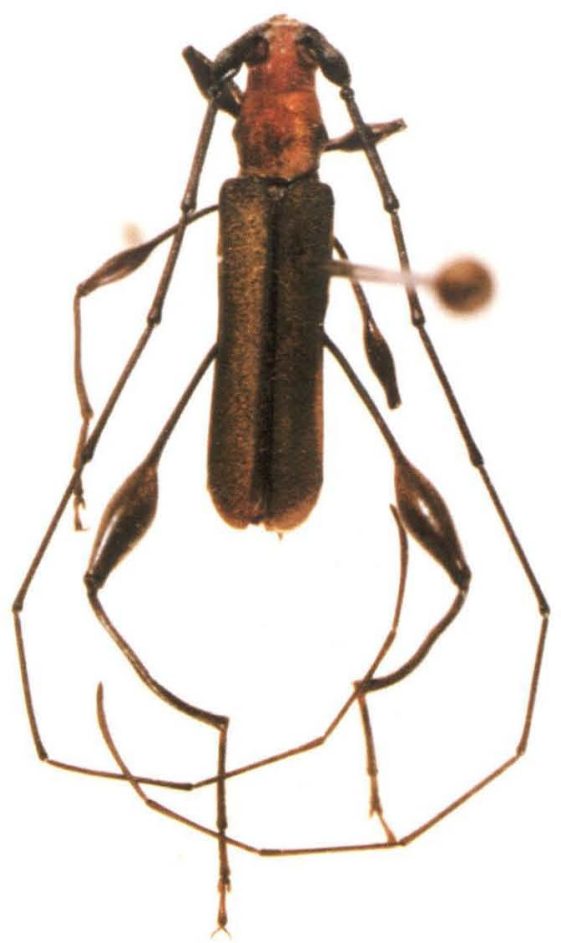

3

Fig. (3) Coremia (Dirocoremia) simplicipes Gounelle, 1911, comprimento $8,5 \mathrm{~mm}$.

Élitros (Fig. 7) subparalelos; ápices arredondados a levemente acuminados; superfície muito densa e uniformemente microcorrugada, pubescência negra pouco visível.

Asa membranosa (Fig. 14): Setor Anterior (SA) curta; r-s oblíqua em direção à s-m; célula da radial subtriangular; Setor (S) e Setor Posterior (SP) ausentes; ramo Ea da Empusal presente; Média Anterior (MA) representada por uma mancha estreita, alongada e pigmentada, atingindo o bordo apical; ramo posterior da segunda anal (2Ab) estende-se até a margem.

Fêmures: clava dos fêmures médios (Figs 1,20) abrupta, com comprimento subigual ao do pedúnculo; fềmures posteriores (Figs 1,22) ultrapassam o ápice elitral pelo ápice do pedúnculo; estes cerca de uma vez e meia tão longo quanto as clavas; estas bem desenvolvidas, abruptas. Tíbias posteriores (Fig. 23) carenadas e sulcadas, mais evidentemente na metade distal; esta com tufo de pêlos desenvolvido, com aspecto algo alongado, ocupando pouco menos da metade do comprimento da tíbia, formado por pincéis de pêlos longos, negros e adensados. Protarsômeros e mesotarsômeros com pêlos curtos, negros e amarelos-dourados na face dorsal; metatarsômeros (Fig. 24) com longas e abundantes cerdas castanhas, decumbentes, nas faces dorsal e laterais; metatarsômeros I-II (Fig. 25) com 

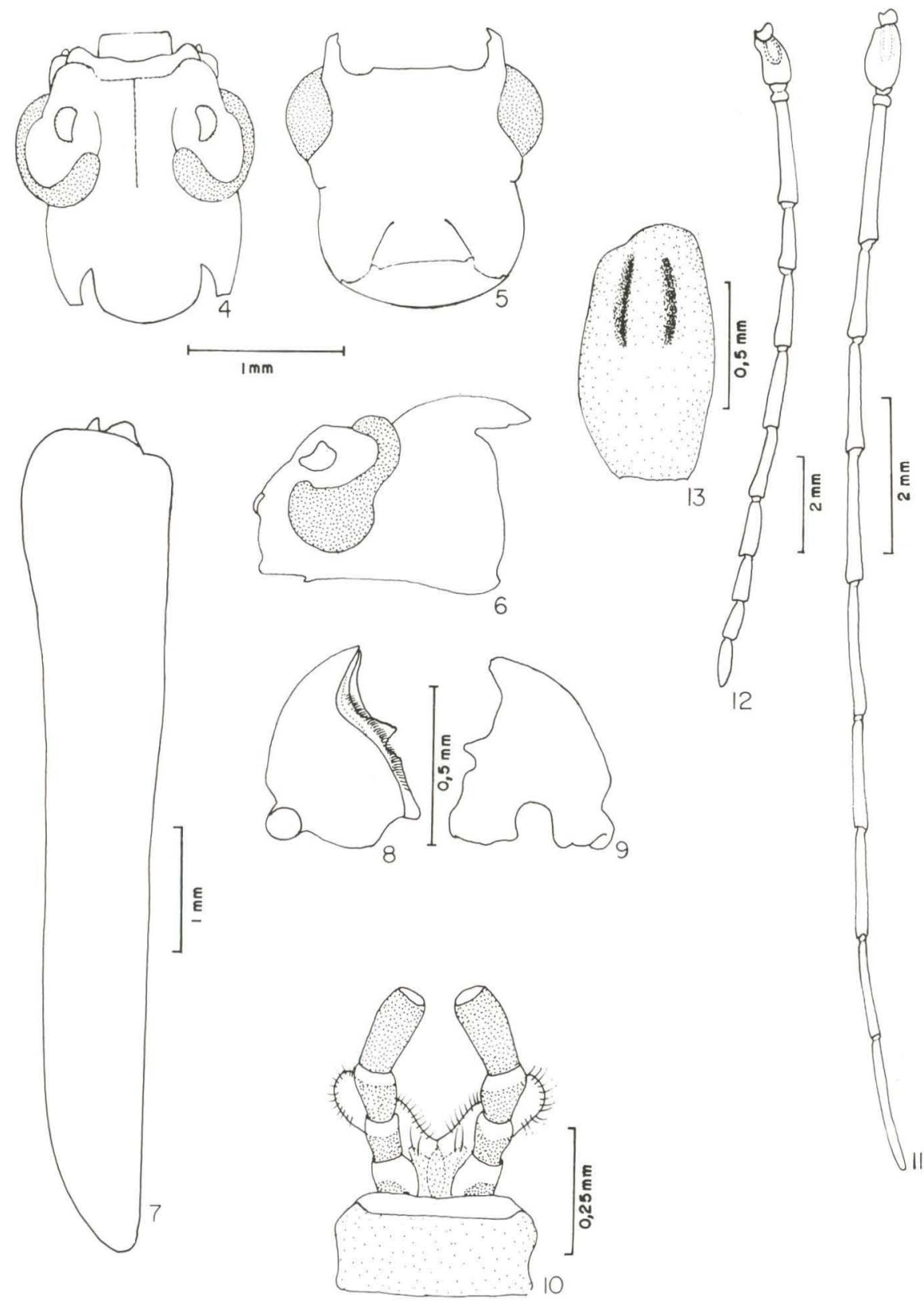

Figs 4-13. Coremia (Dirocoremia) ingae. sp.n., (46) cabeça, dorsal, ventral e lateral: (7) élitro: $(8,9)$ mandỉbula, ventral e dorsal: (10) lábio; (11,12) antena, macho e fềmea: (13) escapo, macho. 
escovas tarsais reduzidas a duas filleiras laterais de pêlos esbranquiçados, curtos, pouco aparentes, com pêlos esparsos ao longo da região mediana.

Terminália. Macho: oitavo tergito (Fig. 27) cerca de uma vez e meia tão largo quanto longo, com pigmentação restrita ao bordo apical, este arredondado com cerdas curtas, pouco adensadas. Oitavo esternito (Fig. 28) reduzido, com comprimento subigual à metade do comprimento do oitavo tergito; bordo apical bissinuado, com cerdas pouco adensadas; apófise esternal tão longa quanto o esternito no seu maior comprimento. Arco ventral (Fig. 29) com apófise cerca de duas vezes mais longa que o comprimento da região bifurcada; esta pouco angulosa; arco dorsal provavelmente ausente restando apenas uma membrana. Tégmen (Fig. 30) com comprimento subigual ao do lobo médio; região anterior aos lobos laterais ("roof" cfe. EHARA 1954) ausente; lobos laterais unidos somente na base por estreita área membranosa, os ápices arredondados com cerdas pouco adensadas; peça anelar convergente, os braços lateris não fusionados, ligados no ápice pela bainha da peça anelar. Lobo médio (Fig. 26): lobo dorsal com ápice arredondado-truncado, o ventral, acuminado; apófises basais quase duas vezes mais longas que a região apical; orifício médio alargado, arredondado; forâmen médio estreitado. Saco interno, ao nível do oríficio médio, com duas peças desenvolvidas, esclerotinizadas, em forma de ganchos, fusionadas na base. Fêmea: oitavo segmento (Figs 33-34) transverso, cerca de uma vez e meia tão largo quanto longo, com bordos laterais subparalelos, o apical arredondado a truncado com cerdas longas e abundantes; apófise esternal cerca de duas vezes mais longa que o esternito. Ovipositor (Figs 31-32): limite entre as regiões proximal e distal do hemisternito IX, marcado por constrição pouco acentuada. Duto espermatecal sem anéis no ponto de ligação com a espermateca; glândula da espermateca mais curta que a espermateca.

Dimensões em mm, macho e fêmea, respectivamente. Comprimento total, 8,5 a 10,0 e 9,17 a 10,0; comprimento do protórax, 1,67 a 1,92 e 1,75 a 2,0; maior largura do protórax, 1,67 a 1,92 e 1,75 a 1,92; comprimento do élitro, 5,92 a 6,92 e 6,67 a 7,17; largura umeral, 1,92 a 2,25 e 2,08 a 2,25.

Discussão. Exemplares desta espécie encontram-se usualmente identificados como machos de Coremia erythromera A.-Serville, 1834. O exame de maior número de exemplares, o estudo da terminália e a comparação com o diapositivo do tipo de Coremia erythromera, revelou tratar-se de uma nova espécie. Coremia ingae, sp.n. é muito semelhante à C. bruchi Gounelle, 1905 distinguindo-se principalmente, por: 1) coloração das antenas, inteiramente vermelho-alaranjadas: 2) protórax com pontuação corrugada, microesculturada; 3 ) clípeo transverso com cerca de um terço do comprimento da fronte, a sutura clipeal sub-reta. Em $C$. bruchi as antenas são negro-acastanhadas, pelo menos nos artículos basais, e o escapo é sempre negro; a pontuação do protórax não tem aspecto corrugado e a superfície não apresenta microescultura; o clípeó subtriangular, pouco mais longo que a fronte na linha média e a sutura clipeal é subangulosa.

Dados biológicos: Prof. F. Giacomel (comunicação pessoal), obteve exemplares desta espécie emergidos de pequenos galhos de Inga sp. (Mimosaceae), provenientes da região de Jaguariaíva, Paraná. 

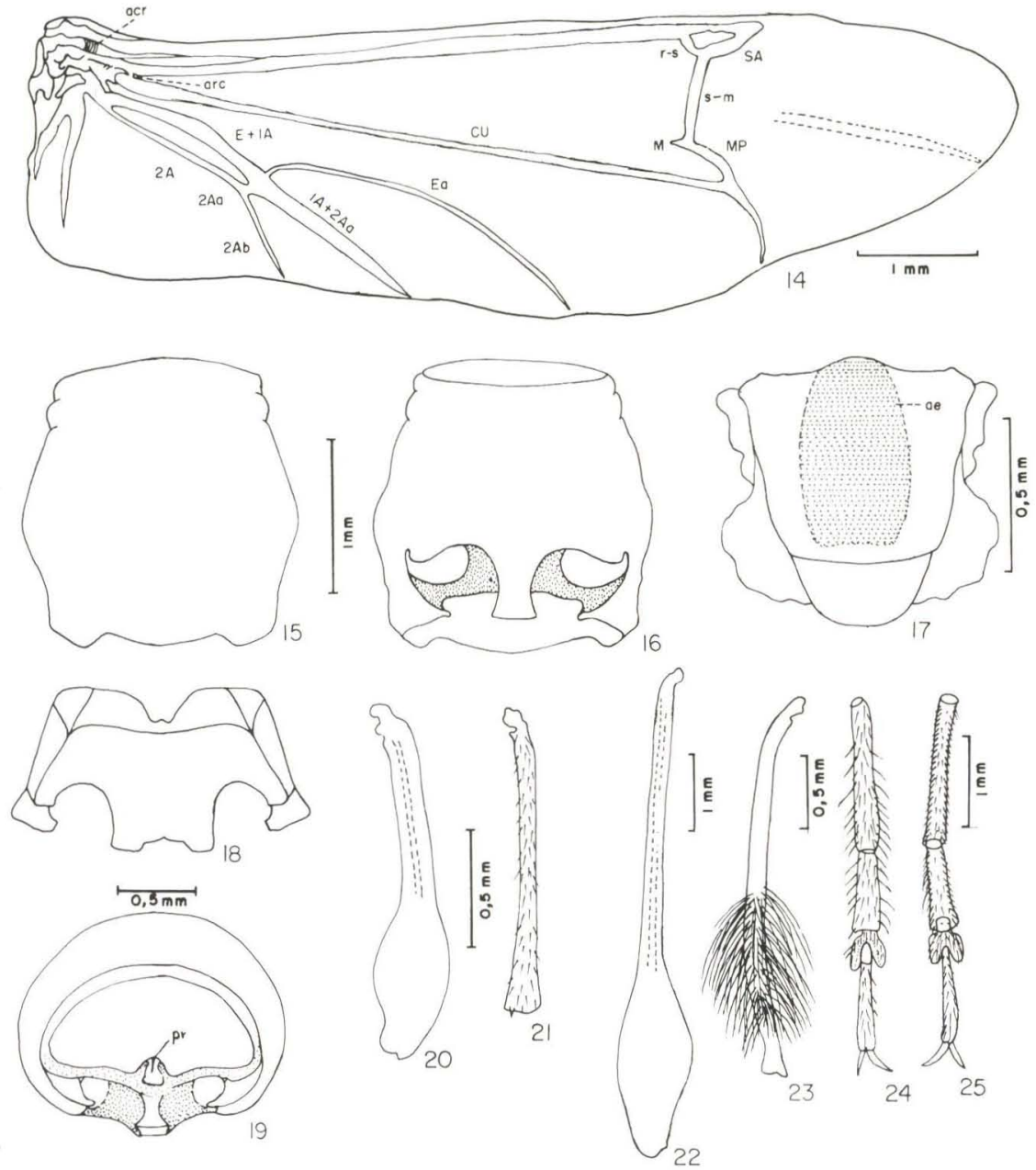

Figs 14-25. Coremia (Drrocorema) ingae. sp.n. (14) Asa membranosa: (15) protórax: (16) prosterno: (17) mesoscuto e escutelo: (18) mesosterno: (19) protórax, vista posterior: (20.21) fêmur e tibia médios: (22.23) fêmur e tíbia posteriores; (24,25) metatarsômeros, dorsal e ventral (acr=área carenada: $\mathbf{a e}=$ área estridulatória; $\mathbf{a r c}=$ árculo $\mathbf{C U}=\mathbf{C u b i t a l} ; \mathbf{E} \mathbf{a}=$ ramo a da $\mathbf{E m p u s a l ;} \mathbf{M}=\mathbf{M e ́ d i a} ; \mathbf{M P}=\mathbf{M e ́ d i a}$

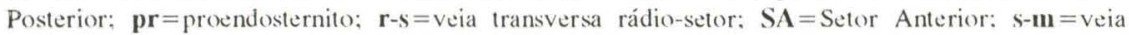
transversa setor média; $\mathbf{1} \mathbf{a}=$ Primeira Anal: $\mathbf{2} \mathbf{A}=$ Segunda Anal: $\mathbf{2 A} \mathbf{a}=$ ramo anterior da Segunda Anal: $\mathbf{2 A b}=$ ramo posterior da Segunda Anal).

Holótipo macho. Brasil, Paruná: Jaguariaíva, 2.XI.1972, Moure e Rosado leg. (DZUP). Parátipos: Brasil, São Paulo: Itu, 1 macho 30.X.1960, Araújo \& Martins leg., 2 machos 6.XI.1960, I macho 13.XI.1960, U. Martins leg. (MZSP). Paraná: Jaguariaíva, 11 machos, 2 fêmeas 1.XI.1971, F. Giacomel leg., 2 machos 2.XI.1972, Moure \& Rosado leg. (DZUP). Rio Grande do Sul: Pareci Novo, 1 fêmea $\left(n^{\circ} 6321\right), 1$ fềmea $\left(n^{\circ} 6322\right), 1$ fềmea $\left(n^{\circ} 6324\right), 1$ fêmea $\left(n^{\circ} 6325\right)$ 
XII.1927, Pe. Buck leg. (MAPA); Porto Alegre, I fềmea (nº6323) 28.XI.1957, Pe. Buck leg. (MAPA). Argentina, Corrientes: San Tomé, 1 fềmea XI. 1937 (MZSP).

\section{Coremia (Dirocoremia) bruchi Gounelle, 1905}

Figs 2, 35

Coremia hruchi Gounelle, 1905: 227.- Bruch, 1912: 198.- Porter, 1923: 498.- Buck. 1959: 591. Coremia (Thalusia) bruchi; Aurivillius, 1912: 335.- Bruch. 1915: 559.- Bosq. 1949: 200.- Blackwelder, 1946: 580.- Bosq \& Ruffinclli. 1951: 14.- Zajciw. 1959: 278.- Zajciw \& Ruffinelli. 1962: 48.- Viana \& Williner, 1973: 10.

Coremia erythromera: Burmeister, 1865: 171.- Frenzel, 1891: 332 (non Audinet-Serville. 1834).

Macho (Fig. 2). Colorido geral negro; antenas negro-acastanhadas pelo menos nos artículos basais, o escapo sempre negro; pernas vermelho-alaranjadas, (exceto as clavas dos fềmures, negras): tegumento com pouco brilho, superfície não corrugada, sem microescultura entre os pontos; pubescência da face dorsal e ventral como em $C$. ingale.

Cabeça (Fig. 35) com comprimento pouco maior que o do protórax; na região posterior levemente constrita. Fronte com comprimento subigual ao do clípeo, este subtriangular, com a borda apical subangulosa. Sutura fronto-clipeal angulosa. Loho ocular inferior com margem superior próxima ao alvéolo antenal. Antenas (Fig. 2), nos machos, ultrapassam o ápice elitral em 4-4,5 artículos, o XI pouco mais longo que o III, levemente apendiculado; nas fêmeas ultrapassam o ápice elitral em 1-2 artículos; o XI com comprimento igual à metade do III.

Protórax com superfície densamente pontuada, não corrugada, sem microescultura entre os pontos. Escutelo com pubescência serícea adensada.

Élitros com pubescência acastanhada não adensada.

Terminália. Macho: Oitavo tergito quase duas vezes mais largo que longo; apófises basais cerca de uma vez e meia tão longas quanto a região apical. Forâmen médio contornado por pigmentação acentuada em forma de Y Fêmea: oitavo segmento quase duas vezes mais largo que longo; apófise esternal cerca de três vezes mais longa que o esternito; limite entre as regiões proximal e distal do hemisternito IX marcado por constrição acentuada.

Demais características como em Coremia ingae.

Dimensões em mm, macho e fêmea, respectivamente. Comprimento total, 6,67 a 9,0 e 8,33 a 9,17; comprimento do protórax, 1,33 a 1,92 e 1,75 a 1,83; maior largura do protórax, 1,33 a 1,83 e 1,67 a 1,75; comprimento do élitro, 4,75 a 6,17 e 5,92 a 6,42: largura umeral, 1,58 a 2,17 e 2,0 a 2,08.

Material-tipo. Foi examinado o diapositivo do síntipo macho, fotografado por J.S. Moure, no The Natural History Museum, Londres. GounElle (1905) examinou numerosos exemplares provenientes das Províncias de Catamarca e Tucumán, Argentina.

Distribuição geográfica. Única espécie do gênero não citada para o Brasil, registrada até o momento apenas para Argentina e Uruguai. De acordo com registros de literatura a espécie é também mencionada para: Tucumán, Mendoza 


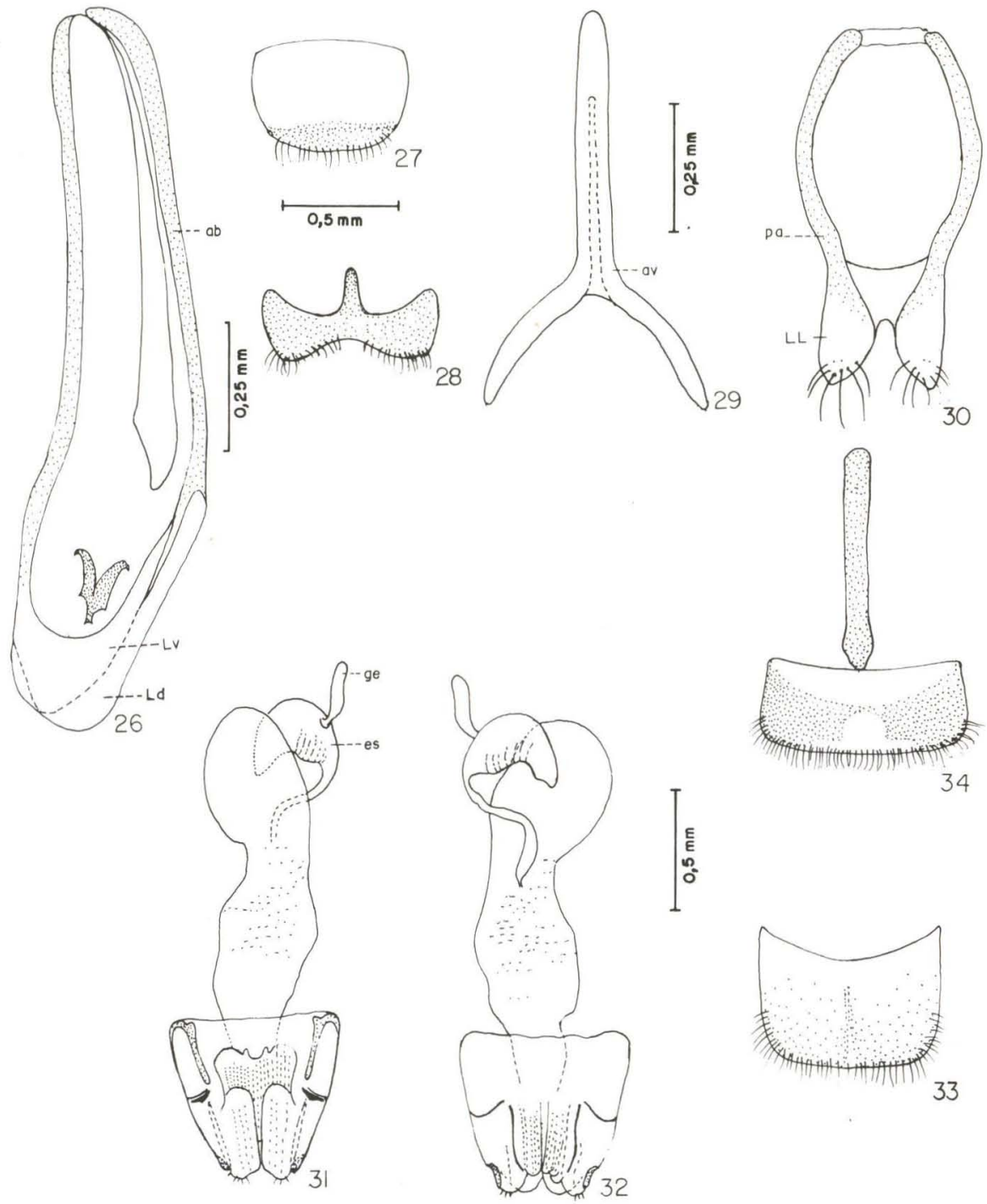

Figs 26-34. Coremia (Dirocoremia) ingae, sp.n. (26-30) Terminália masculina: (26) lobo médio; (27) oitavo tergito: (28) oitavo esternito; (29) arco ventral; (30) tégmen: (31-34) terminália feminina; (31-32) ovipositor (hemisternito IX. dorsal e ventral): (33) oitavo tergito: (34) oitavo esternito, (ab=apófises basais; $\mathbf{a v}=$ arco ventral; es=espermateca; $\mathbf{g e}=$ glândula espermatecal; $\mathbf{L d}=$ lobo dorsal: $\mathbf{L L}=$ lobos laterais; $\mathbf{L v}=$ lobo ventral: pa= peça anelar: $\mathbf{I X}=$ hemisternito 9).

(BruCh 1912), Santiago del Estero, La Rioja, San Cristobal, Mendoza (ZaJciw 1959), na Argentina e para Colônia, Nueva Palmira, Rio Negro, San José, Payssandú (BoSQ \& RUfFINELli 1951), Departamento de Rio Negro, San Javier, Las Piedras (Zajciw, 1959), Payssandú, Rio Negro, Bellaco, Soriano, Mercedes, 
San José: Puerto Arazati, Rincón de la Bolsa, Colonia: Carmelo, Nueva Palmira (ZAJCIW \& Ruffinelli 1962) no Uruguai. Tive em mãos dois exemplares machos da Bolívia, coligidos por J.F. Zikán (MZSP), procedência a confirmar.

Material examinado. Argentina, Salta: La Candelaria, 2 machos 15.I. 1965, A. Mesa \& R. Saldulski leg. (MNRJ); Urundel (Puerto Pepe Aji), 1 fêmea 16.XII.1966, C.S. Carbonell, P.R. San Martin \& M.A. Monné leg. (MNRJ); Catamarca: El Rodeo, 1 fêmea I. 1942 (MAPA); Cordoba: Arguello, 1 fêmea XII. 1945, (DZUP); Dean Funes, 3 machos 1 fêmed, 3.XII. 1940, 1 macho 1 fêmea, I. 1942 (MAPA); San Luis, 2 machos XI. 1941, Pe. Buck leg. (MAPA); Soto, 1 fềmea I.1946, Prosen leg. (MZSP); Entre Rios: Vila Elisa, 1 macho III. 1974 (MZSP). Uruguai, Montevideo (Santiago Vasques), 1 macho 1 fềmea, 24.XII. 1961, C.S. Morey leg. (MNRJ).

\section{Coremia (Dirocoremia) simplicipes Gounelle, 1911}

Figs $3,36-42$

Coremia simplicipes Gounelle, 1911: 183, 1 fig.- Blackwelder, 1946: 580.- Buck, 1959: 591.

Coremia (Coremia) simplicipes; Aurivillius, 1912: 335.- Bosq. 1943: 108

Coremia (Lathusia) simplicipes; Zajuiw. 1959: 281.- Zajciw. 1965: 9.

Macho (Fig. 3). Cabeça vermelho-alaranjada com a área malar e clípeo castanhos a negros; protórax usualmente vermelho-alaranjado na metade anterior e negro-acastanhado na posterior, em alguns exemplares inteiramente vermelhoalaranjado; antenas, pernas e face ventral do corpo negras: élitros opacos, cinza a cinza-esverdeados, revestidos de pilosidade serícea.

Cabeça (Fig. 36) com comprimento pouco maior que o do protórax; na região posterior, acentuadamente constrita; pontuação grossa e adensada, mais corrugada na fronte, a superfície sem microescultura, brilhante; pilosidade pouco aparente. Fronte cerca de duas vezes e meia mais larga que longa. Área malar reduzida, em sua menor largura subigual à metade do diâmetro do lobo ocular inferior; este com a margem superior afastada do alvéolo antenal. Tubérculos anteníferos arredondados a ligeiramente acuminados. Sutura fronto-clipeal recurva, levemente angulosa. Mandíbulas acuminadas e curvadas no ápice; franja de pêlos aparente. Lábio: lígula no bordo apical levemente sinuoso.

Antenas (Fig. 3) ultrapassam o ápice elitral em 5,5-6 artículos; escapo (Fig. 39) na base com única depressão longitudinal, algo alargada e bem impressa; artículos V-VI mais longos que o III; VII-X com comprimentos subiguais e decrescentes; XI subigual ao III, apendiculado; nas fêmeas ultrapassam o ápice elitral em 2-3 artículos; o XI com comprimento maior que a metade do III.

Protórax (Fig. 37) com comprimento subigual à largura; com os bordos laterais ao nível do meio com tubérculos algo aguçados, mais evidentes na fêmea; disco algo irregular com duas elevações látero-posteriores apenas manifestas; pontuação grossa, bem marcada, esparsa no disco e adensada para as regiões laterais, a superfície sem microescultura, brilhante; pilosidade esbranquiçada a amarelo-dourada adensada, mais evidente para as regiões laterais. Processo prosternal estreito, não expandido para o ápice. Escutelo uma vez e meia tão largo 

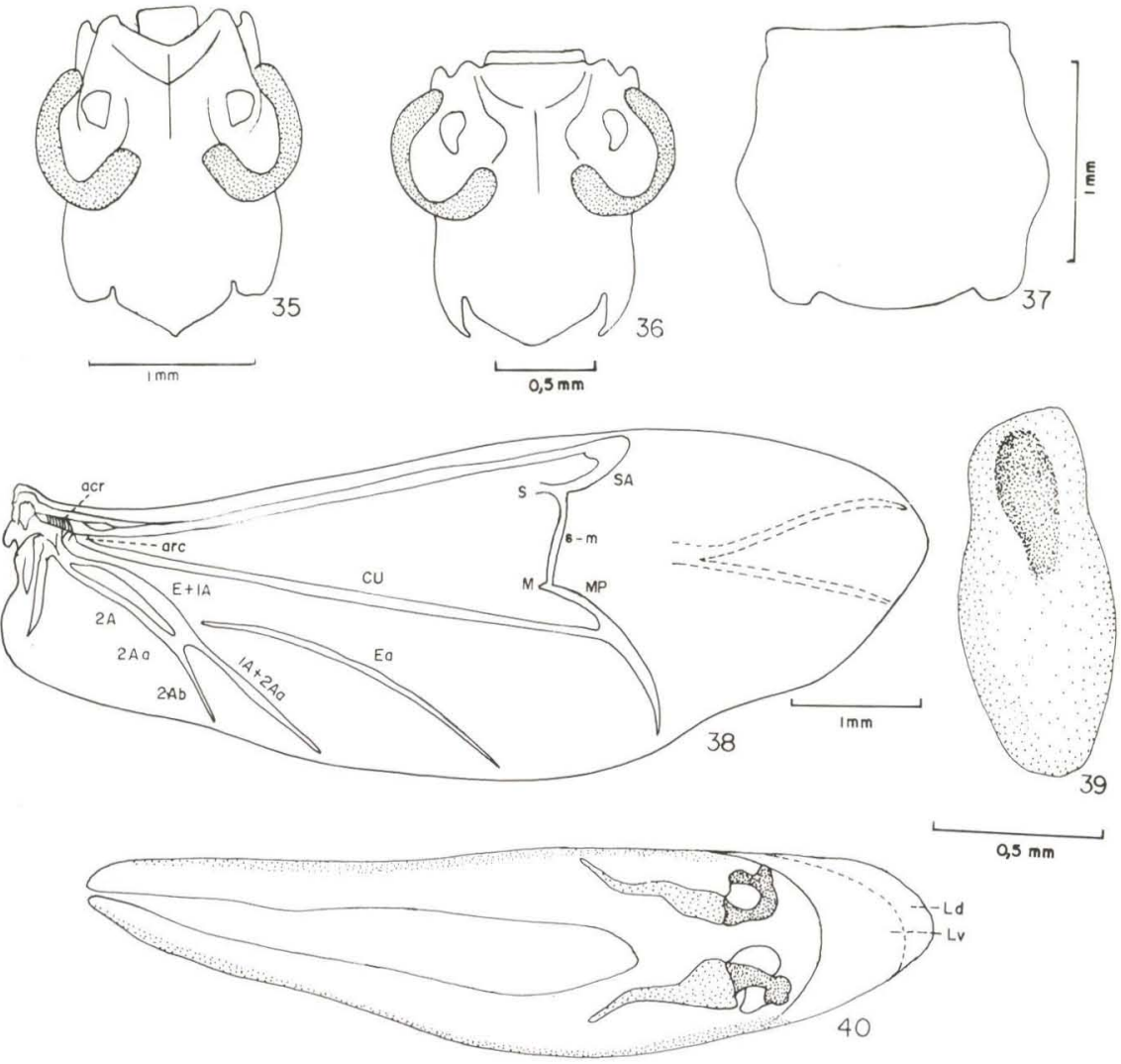

$0,5 \mathrm{~mm}$
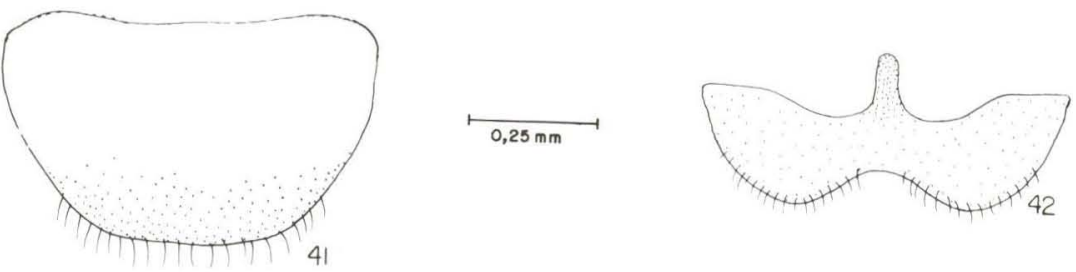

Figs 35-42. (35) Coremia (Dirocoremia) bruchi Gounelle, 1905, cabeça dorsal: (36-42) Coremia (Dirocoremia) simplicipes Gounelle, 1911. (36) Cabeça dorsal; (37) protórax; (38) asa membranosa: (39) escapo, macho; (40-42) Terminália masculina: (40) lobo médio, dorsal; (41) oitavo tergito; (42) oitavo esternito. (acr=área carenada; $\mathbf{a r c}=$ árculo; $\mathbf{C U}=$ Cubital; $\mathbf{E a}=$ ramo a da Empusal; $\mathbf{L} \mathbf{d}=10$ bo dorsal; $\mathbf{L v}=$ lobo ventral: $\mathbf{M}=$ Média; $\mathbf{M P}=$ Média Posterior: $\mathbf{S}=$ Setor; $\mathbf{S A}=$ Setor Anterior; $\mathbf{S}-\mathbf{m}=$ veia transversa setor-média; $\mathbf{1 A}=$ Primeira Anal; $\mathbf{2} \mathbf{A}=$ Segunda Anal; $\mathbf{2} \mathbf{A} \mathbf{a}=$ ramo anterior da Segunda Anal; $\mathbf{2 A b}=$ ramo posterior da Segunda Anal). 
quanto longo, superfície microcorrugada, revestida por pubescência amareloesbranquiçada.

Élitros arredondados no ápice, com pubescência serícea.

Asa membranosa (Fig. 38): transversa (r-s) ausente, célula da radial aberta; Setor (S) evanescente; Setor Posterior (SP) representada por mancha estreita; ramo Ea da Empusal não ligada à $\mathrm{E}+1 \mathrm{~A}$.

Pernas (Fig. 3): fêmures médios com as clavas pouco mais longas que a metade do comprimento do pedúnculo, não fortemente abruptas: os posteriores alongados, ultrapassam o ápice elitral pelo comprimento das clavas; estas algo alongadas, desenvolvidas, não fortemente abruptas. Tíbias posteriores cilíndricodeprimidas, com sulcos e carenas pouco manifestas, sem tufo de pêlos; metade distal algo arqueada, com cerdas acastanhadas mais abundantes nas fêmeas; limite entre a metade basal e distal marcado por constrição mais, ou menos, acentuada, a região imediatamente anterior à constrição um pouco dilatada.

Terminália. Macho: oitavo tergito (Fig. 41) quase duas vezes mais largo que longo. Apótise esternal do oitavo esternito (Fig. 42) quase tão longa quanto o esternito no seu maior comprimento. Arco ventral com apófise cerca de uma vez e meia tão longa quanto o comprimento da região bifurcada; esta em arco amplo, levemente anguloso. Lobo médio (Fig. 40): lobos dorsal e ventral com ápices arredondados. Saco interno, entre o orifício médio e o forâmen médio, com dois pares de peças esclerotinizadas, cada par composto de duas partes que se encaixam na base: uma curta, em forma de gancho com ápice fortemente acuminado e curvado, a outra alongada, com a base alargada, estreitada para o ápice. Fêmea: Apófise esternal cerca de três vezes mais longa que o esternito. Duto espermatecal forma anéis no ponto de ligação com a espermateca.

Demais características como em $C$. ingae.

Dimensões, em mm, macho e fêmea, respectivamente. Comprimento total, 6,0 a 8,83 e 6,58 a 9,50; comprimento do protórax, 1,08 a 1,67 e 1,17 a 1,75; maior largura do protórax, 1,25 a 1,83 e 1,42 a 1,92; comprimento do élitro, 4,50 a 6,33 e 5,08 a 6,83; largura umeral, 1,50 a 2,0 e 1,58 a 2,25.

Discussão. Distingue-se de Coremia bruchi e Coremia ingae principalmente: 1) coloração do pronoto, antenas e pernas; 2) élitros revestidos de pubescência serícea; 3) escapo, nos dois sexos, com única depressão basal; 4) conformação do protórax, com tubérculos laterais mais evidentes; 5) célula da radial aberta; 6) clavas posteriores algo alongadas, não fortemente abruptas; 7) tíbias posteriores sem tufo de pêlos. Apesar destas diferenças, a inclusão de $C$. simplicipes neste subgênero justifica-se: 1) fronte evidentemente deprimida, com os bordos laterais elevados e arredondados, formando um rebordo nítido entre a fronte e a área malar; 2) antenas com evidente dimorfismo, as do macho com artículos cilíndrico-alongados, não intumescidos, com artículo XI subigual ao III em comprimento; 3) padrão do ovipositor. As três espécies apresentam ainda um padrão semelhante de proendosternito (subtriangular) e o processo mesosternal com sistema de encaixe para o metasterno.

Material-tipo. Os síntipos encontram-se depositados no Muséum National 
d'Histoire Naturelle, Paris, e dois foram estudados através de diapositivos feitos pelo Pe. J.S. Moure. Gounelle (1911) descreveu a espécie com base em um macho de Condeúba, Bahia e uma fêmea originária de Jataí, Goiás.

Material examinado. Brasil, Paraíba: Juazeirinho (Soledade), 1 macho 24.III.1965, A.G.A.Silva leg.; Serra Branca, 1 macho 4.III. 1981, C.S. Carbonell leg. (MNRJ). Bahia: Condeúba, 1 fêmea XII. 1975, S. Souza leg. (DZUP). Minas Gerais: Pedra Azul, 1 macho 1 fêmea, XII.1970, Seabra \& Oliveira leg. (MNRJ). Mato Grosso do Sul: Bodoquena, 1 fêmea XI.1941, Com. I.O.C. leg. (MNRJ). Espírito Santo: Baixo Guandu, 3 machos 5 fêmeas X.1971, P.C. Elias leg. (MZSP), 1 fêmea 8.XI.1971, C. Elias leg. (DZUP); Itapina, 2 machos 5 fêmeas, 16-21.XI.1970, C. Elias leg. (DZUP). São Paulo: Marília, 1 macho XI.1945, 1 macho 2 fêmeas, XI.1945, Nick leg. (MZSP). BolíviA, Santa Cruz: Buena Vista (Ichilo) 3 fêmeas II. 1950, Martinez leg. (MZSP). ArgentinA, Salta: Carapari, 1 macho 20.I.1945, Bridarolli S.J. leg. (MAPA); Urundel, I fêmea II.1945 (MZSP).

AGRADECIMENTOS. Em especial a Dra. Dilma Solange Napp pela orientação na dissertação da tese de mestrado, amizade e constante estímulo profissional; ao Dr. Pe. Jesus S. Moure pelas sugestões na elaboração dos nomes do subgênero e espécie novos e ao Dr. Albino M. Sakakibara pelas fotografias do material.

\section{REFERÊNCIAS BIBLIOGRÁFICAS}

Aurivillius, C. 1912. Cerambycidae: Cerambycinae, 39, in Coleopterorum Catalogus, Berlin, W. Jung, 574 p.

BLACKWELDER, R.E. 1946. Checklist of the Coleopterous insects of Mexico, Central America, the West Indies and South America. Bull.U.S. nat. Mus., Washington, 185 (4): 551-763.

BosQ, J.M. 1943. Agregados al catálogo de los longicórnios de la República Argentina. Revta argent. Zoogeogr. 3 (3): 103-112.

1949. Anotaciones relativas a una lista de fauna local sobre Cerambícidos argentinos. Revta Soc. ent. argent. 14 (4): 194-203.

BosQ, J.M. \& A. Ruffinelli. 1951. Notas para el catálogo de los Cerambícidos del Uruguay. Comun. zool. Mus. Hist. Nat., Montevideo, 3 (62): 1-32.

Bruch, C. 1912. Catálogo sistemático de los Coleópteros de la República Argentina, Pars VIII, Familia Cerambycidae. Revta Mus. La Plata 18: 179-226.

1915. Suplemento al catálogo sistemático de los coleópteros de la República Argentina (Addenda, corrigenda y resumen). Revta Mus. La Plata 19 (2): 551-561.

Buck, P. 1959. Cerambycidae in der Sammlung des Instituto Anchietano de Pesquisas. Pesquisas, P. Alegre, 3: 577-609.

Burmeister, H.C. 1865. Longicornia Argentina. Systematische Übersicht der Bockkäfer der La Plata-Staaten. Stettin. ent. Ztg. 26: 156-181. 
1879. Briefliche Mittheilungen (3. Nachträge zu dem Aufsatz: Longicornia Argentina, Zeitung 1865, S. 156 ff.) Stett. ent. Z. 26 156-181.

EHARA, S. 1954. Comparative anatomy of male genitalia in some Cerambycidae beetles. Jour. Fac. Hokkaido Univ. 12 (1-2): 61-115.

FrenZEL, E. 1891. Übersicht über eine Coleopterensammlung von Córdoba in Argentinien. Ent. Nachr. 17 (21): 326-333.

GoUNELLE, E. 1905. Description d'un nouvelle cerambycidae nouveau appartenant au genre Coremia et tableau synoptique de ce genre (Col.). Bull. Soc. ent. France 10: 227-228.

1911. Liste des cérambycides de la région de Jatahy, État de Goyaz, Brésil. Ann. Soc. ent. France. 80: 1-150.

IUGA,V.G. \& A. RoscA. 1962. La morphologie de l'apex abdominal ches les Cerambycidae (Col.), comparé à celui Hymenoptères. Trav. Mus. Hist. "Gr. Antipa" 3: 101-156.

Lindroth, C.H. \& E. Palmen. 1970. Coleoptera, p.80-88. In: Tuxen, S.L. (ed.) Taxonomist's glossary of genitalia in insects. Copenhagen, Munksgaard, $359 \mathrm{p}$.

MARINONI, R.C. \& L.M. AlmeidA. 1983. Sobre a venação alar em Coccinellidae e Cerambycidae (Coleoptera). Revta bras. Ent. 27 (3/4): 267-275.

Marques, M.I. 1994. Revisão do gênero Coremia Audinet-Serville, 1834 (Coleoptera, Cerambycidae, Compsocerini). Tese de Mestrado, não publicada, Universidade Federal do Paraná, Curitiba, IX +154p.

PORTER, C. E. 1923. Notas breves sobre longicórneos chilenos. Revta chil. Hist. nat. 25: 495-501, 2 figs.

ViANA, M. J. \& G.J. Williner. 1973. Evaluación de la fauna entomológica y aracnológica de las provincias centrales y cuyanas. Acta Scient. (Entom.) 7: $1-30$.

Za.JcIW, D. 1959. Revisão do gênero Coremia A.-Serville, 1834 (Coleoptera, Cerambycidae, Cerambycinae). Studia Ent. 2 (1-4): 271-284, 3 figs. 1965. Contribuições para o estudo da fauna dos longicórneos do Estado da Paraiba (Coleoptera, Cerambycidae). Bolm. Soc. cearense Agron. 6: 5-21 Zajciw, D. \& A. Ruffinelli. 1962. Fauna de los Cerambícidos del Uruguay. Bol. Fac. Agron., Montevideo, 60: 48-49.

Recebido em 30.IV.1994; aceito em 13.VII.1994 